\title{
Sexual behaviour in travellers abroad attending an inner-city genitourinary medicine clinic
}

\author{
R Mendelsohn, L Astle, M Mann, M Shahmanesh
}

\begin{abstract}
Objective: To investigate frequency of sexual encounters with new partners abroad in patients attending a genitourinary clinic (GUM).

Methods: In a case series 464 attenders at a genitourinary medicine clinic completed an anonymous self-administered questionnaire, if they had been abroad recently, enquiring about sexual behaviour abroad.

Results: $28 \cdot 4 \%$ of subjects admitted to sex with a new partner abroad with only 41.7 per cent consistently using condoms. There were no significant differences in condom use for gender, ethnicity or type of visit and relationship. Twenty-nine per cent of those admitting to sex abroad had more than one partner. The risk of multiple partners was not associated with gender, ethnicity, type of visit (holiday or business) or type of relationship (heterosexual or homosexual). The first partner abroad for $63 \%$ of men and $62.5 \%$ of women was of a nationality other than that of United Kingdom residents. Non-Caucasians and homosexuals were significantly more likely to have first partners abroad from outside the UK than Caucasians and heterosexuals respectively. Conclusion: The occurrence of casual sex abroad in GUM attenders suggests that further research is needed to establish targetable risk factors for this type of behaviour amenable to change through health promotion.

(Genitourin Med 1996;72:43-46)
\end{abstract}

Keywords: travel; ethnicity; sexual behaviour

\section{Introduction}

National surveillance ${ }^{1}$ data for the UK indicates that up to and including the end of September $1995,13 \cdot 1 \%$ of patients with HIV1 infection acquired the virus abroad heterosexually. This group represents the third largest, by exposure category. As previously observed $^{2}$ such reports do not distinguish between those patients originating from abroad, expatriates resident overseas on a long term basis and short term travellers such as holiday makers. Concerns have been raised in the past regarding the risks to travellers overseas of HIV infection ${ }^{345}$ and a number of published studies have looked at risk behaviour in travellers within STD clinic populations ${ }^{67}$ in London.

No studies have been reported in the UK outside London. We set out, therefore, to investigate casual sexual activity abroad with new partners in travellers who subsequently attended a Birmingham genitourinary clinic, and relate this to ethnicity, type of visit and condom use.

\footnotetext{
Department of

Genitourinary

Medicine, Whittall

Street Clinic, Whittall

Street, Birmingham

B4 6DH

R Mendelsohn

L Astle

M Mann

M Shahmanesh

Address correspondence to Dr M Shahmanesh.

Accepted for publication

9 November 1995
}

\section{Methods}

The Department of Genitourinary Medicine (GUM) at Birmingham General Hospital is a large clinic situated in the city centre and serves all the Birmingham Health Districts. Patients, aged over 16 years, presenting to the GUM clinic with new problems, from January to April and from July to October 1993, were asked if they had been abroad in the last six months, and were recruited to the study if they had done so.
Subjects were asked to complete a selfadministered, anonymous questionnaire. Details of place of residence, place of birth, age, destination, the type of visit (holiday or business) and date of travel were sought. The subjects were asked to classify themselves into a racial/ethnic group of either White, AfricanCaribbean, Asian or Other.

If they admitted to having had sex abroad during the trip they were asked if this was with their regular partner or a new partner. If it was with a new partner then further information about gender, use of condoms and country of origin was sought.

The outcomes of interest were: number of new partners abroad, whether the partners were of UK or non-UK origin and condom use. Data was analysed by gender, race/ethnicity, type of visit and same/opposite sex relationship.

Statistical analysis was performed on Epiinfo using the chi square test on differences in proportion. Statistical significance was set at the 5\% level. Ethical approval had been obtained from the local ethical committee and the patients gave informed consent.

\section{Results}

Characteristics of subjects

Four hundred and sixty four GUM clinic patients, aged between 17 and 69 years had travelled during the period of interest and were therefore recruited to the study (table 1). During this period 6320 patients attended the clinic as a new patient or as an old patient with a new problem. The questionnaire was not 
Table 1 Characteristics of subjects

\begin{tabular}{lcc}
\hline & $\begin{array}{l}\text { Subjects }<45 \text { years } n=436 \\
(\%)\end{array}$ & $\begin{array}{l}\text { Subjects }>45 \text { years } n=28 \\
(\%)\end{array}$ \\
\hline $\begin{array}{l}\text { Age (years) } \\
\text { median (range) }\end{array}$ & $\begin{array}{l}25(17-45) \\
\text { Males }\end{array}$ & $52(46-69)$ \\
Ethnicity/race & $220(50 \cdot 5)$ & $20(71 \cdot 4)$ \\
Caucasian & $337(77 \cdot 5)$ & $22(78 \cdot 6)$ \\
Afro-Caribbean & $57(13 \cdot 1)$ & $5(17 \cdot 8)$ \\
Asian & $22(5 \cdot 1)$ & $1(3 \cdot 6)$ \\
Other & $19(4 \cdot 4)$ & \\
Residency & & $22(81 \cdot 5)$ \\
Birmingham & $326(75 \cdot 3)$ & $2(7 \cdot 4)$ \\
W. Midlands & $56(12 \cdot 9)$ & $3(11 \cdot 1)$ \\
UK & $46(10 \cdot 6)$ & - \\
Abroad & $5(1 \cdot 2)$ & $9(32 \cdot 1)$ \\
Sex abroad & $124(28 \cdot 4)$ & $19(67 \cdot 9)$ \\
Yes & $312(71 \cdot 6)$ & \\
No & &
\end{tabular}

Table 2 Destination and condom use

\begin{tabular}{lccc}
\hline Destination & Person/visits & Sex abroad (\%) & Condom use (\%) \\
\hline Europe & 232 & $54(23 \cdot 3)$ & $20(37)$ \\
Americas & 40 & $11(27 \cdot 5)$ & $4(36 \cdot 4)$ \\
Australia & 2 & 0 & - \\
Asia & 10 & 0 & $1(33)$ \\
S.E. Asia & 6 & $3(50)$ & $1(25)$ \\
Caribbean & 17 & $0(23 \cdot 5)$ & $2(100)$ \\
Africa & 6 & $2(22 \cdot 2)$ & $28(37 \cdot 8)$ \\
Other & 9 & $74(22 \cdot 9)$ & \\
Totals & 322 &
\end{tabular}

Table 3 Number of casual sexual partners abroad

\begin{tabular}{llccc}
\hline & $\begin{array}{l}\text { One } \\
\text { Partner } \\
(\%)\end{array}$ & $\begin{array}{l}>1 \\
\text { Partner } \\
(\%)\end{array}$ & Total & Significance \\
\hline $\begin{array}{l}\text { Gender } \\
\text { Male }\end{array}$ & $54(68 \cdot 4)$ & $25(31 \cdot 6)$ & 79 & NS \\
Female & $31(75 \cdot 6)$ & $10(24 \cdot 4)$ & 41 & \\
$\begin{array}{l}\text { Racelethnicity } \\
\text { Caucasian }\end{array}$ & $66(68 \cdot 8)$ & $30(31 \cdot 2)$ & 96 & \\
Afro-Caribbean & $10(77)$ & $3(23)$ & 13 & \\
Asian & $7(88)$ & $1(12)$ & 8 & NS \\
Other & $2(66 \cdot 6)$ & $1(33 \cdot 4)$ & 3 & NS \\
$\begin{array}{l}\text { Type of visit } \\
\text { Holiday }\end{array}$ & $60(70 \cdot 6)$ & $25(29 \cdot 4)$ & 85 & NS \\
Business & $13(86 \cdot 7)$ & $2(13 \cdot 3)$ & 15 & \\
Heterosexual & $73(73)$ & $27(27)$ & 100 & \\
Homosexual & $7(53 \cdot 8)$ & $6(46 \cdot 2)$ & 13 & \\
\hline
\end{tabular}

Table 4 Condom use with casual sex abroad

\begin{tabular}{lcccc}
\hline & $\begin{array}{l}\text { Condom } \\
\text { used number } \\
(\%)\end{array}$ & $\begin{array}{l}\text { Condom not } \\
\text { used number } \\
(\%)\end{array}$ & Total & Significance \\
\hline $\begin{array}{l}\text { Gender } \\
\text { Males }\end{array}$ & $31(41 \cdot 3)$ & $44(58 \cdot 7)$ & 75 & NS \\
Females & $17(42 \cdot 5)$ & $23(57 \cdot 5)$ & 40 & \\
$\begin{array}{l}\text { Racelethnicity } \\
\text { Caucasians }\end{array}$ & $39(43 \cdot 3)$ & $51(56 \cdot 7)$ & 90 & \\
Afro-Caribbeans & $3(21 \cdot 4)$ & $11(78 \cdot 6)$ & 14 & \\
Asians & $5(62 \cdot 5)$ & $3(37 \cdot 5)$ & 8 & NS \\
Other & $1(50)$ & $1(50)$ & 2 & \\
Type of visit & $34(40)$ & $51(60)$ & 85 & NS \\
Holiday & $6(42 \cdot 9)$ & $8(57 \cdot 1)$ & 14 & NS \\
Business & $42(42 \cdot 4)$ & $57(57 \cdot 6)$ & 99 & 9 \\
Heterosexual & $4(44 \cdot 4)$ & $5(55 \cdot 6)$ & 9 & Hosexual \\
Homose & & & & \\
\hline
\end{tabular}

* 4 subjects stated that they experienced non-penetrative safe sex with new partners and were thus excluded from the analysis. offered to patients on some days. Thus it is possible that not all eligible subjects were approached. Those recruited accounted for $7 \cdot 3 \%$ of this population and there was no preselection.

Three quarters of study subjects were Birmingham residents and 1 in 10 attenders was resident outside the West Midlands Region at the time of the study. One hundred and twenty four $(28.4 \%)$ subjects admitted to having sex with a new partner abroad.

Subjects were excluded from further analysis if their age fell outside the entry criteria, $(17-45)$ or they lived abroad. The 28 subjects, who were aged 46 years or more did not differ significantly from the study group except in place of birth. There were five non-UK residents, of whom four had met someone new whilst abroad, with only one person having used a condom.

\section{Destination and condom use}

Sub-group analysis, by destination, was carried out for those subjects who had travelled within a particular continental area and, if they had casual sex there, it was limited to one partner only (373 subjects). Many subjects visited more than one country during the period of study, either within the same trip or during a number of travels. In order to include all separate visits in an analysis of destinations, the quantity "person visits" was used (person visits $=$ number of persons $\times$ number of visits). This is a cumulative measure. Thus, there were 232 person visits to European destinations, which accounted for $72 \%$ of all visits abroad, for this sub-group. These involved sex with a new partner in $23.3 \%$ with under half (37\%) reporting consistent condom use (table $2)$. The numbers visiting the other destinations were much lower. For example there were only six person visits to Africa (mainly Sub-Saharan). For this particular sub-group none reported having a new partner while there. Overall there were 322 person visits abroad in the sub-group analysis by destination as defined above. These involved casual sex abroad with a new partner in $22.9 \%$ and in only $37 \cdot 8 \%$ of encounters were condoms used consistently.

\section{Numbers of partners}

Analysis by number of new partners abroad during the study period (table 3 ) showed that 35 out of the $120(29 \%)$ of those admitting to sex abroad with a new partner, had more than one partner, either during one trip or a number of trips abroad. $31.6 \%$ of males and $24.4 \%$ of females had multiple partners (not significant) and 30 out of $96(31 \cdot 2 \%)$ Caucasians and 5 out of $24(20 \cdot 8 \%)$ non-Caucasians had more than one partner abroad (not significant). There was also no significant difference between those with multiple partners and those with a single partner with regards to type of visit and type of relationship (heterosexual or homosexual).

Country of origin of partners

The country of origin for first and second partners were available for 115 out of 120 first 
partners and 17 out of 21 second partners. Only one subject volunteered the country of origin for the third partner. Comparison of the proportions of UK to non-UK origin of first (43 out of 119 respectively) and second partners ( 5 out of 17 respectively) showed no significant difference. Of men $37 \%$ and of women $37 \cdot 5 \%$ had a first partner from the UK. For Caucasians, 40 out of 93 (43\%) first partners were from the UK and in AfricanCaribbeans, 1 out of 12 first partners was declared to be from the UK (not significant). However, comparison of Caucasians with non-Caucasians as a group (3 out of 22 of African-Caribbeans, Asians and "Others"), showed that the former were approximately three times more likely to have a UK first partner $(p=0.02$ RR $=3.1595 \%$ CI $1 \cdot 07-9 \cdot 26)$. Homosexuals were also more likely to have had sex with a new partner abroad who was not from the UK compared with heterosexual encounters $(p=0.012)$.

\section{Condom use with new partners abroad}

Analysis of condom use by gender, ethnicity, type of visit and relationship (table 4) showed that a similar proportion of males $(41 \cdot 3 \%)$ and females $(42 \cdot 5 \%)$ consistently used condoms. There was a trend towards greater condom use in Caucasians $(43.3 \%)$ compared with African-Caribbeans $(21 \cdot 4 \%)$ although this difference did not reach significance. Condom use did not differ significantly for type of visit or homosexual compared to heterosexual relationship.

\section{Discussion}

The reporting of the prevalence of sexual risktaking behaviour will depend on the setting, the date and the methodology of the study. For example in a series of 599 attenders at a Norwegian $^{8}$ STD clinic (1989), it was found that $41 \%$ of subjects had casual sex abroad. Sixty seven percent of Swiss tourists visiting Africa, Latin America and the Far East between 1987 and 1989 had casual sex, in half the cases with a prostitute. ${ }^{9}$ Several UK-based studies have been published. In a community based study $^{10}(1992)$ using a random sample taken from a semi-rural general practice (Nottingham) age-sex register it was found that $66 \%$ of the sample had reported travel abroad with only $5 \%$ admitting to casual sex with a new partner abroad.

As expected, studies carried out in clinic or hospital out-patient settings find much higher levels of risk behaviour. For example a seroprevalence study ${ }^{2}$ carried out in the London Hospital for Tropical diseases out-patients department (1988-90) found that $72.9 \%$ of heterosexual travellers (who had been abroad for less than two years) had one or more sexual partners from a country in which HIV was transmitted by heterosexual contact. A study carried out in a London GUM clinic ${ }^{6}$ in 1991, involving 250 consecutive attenders showed that $32 \%$ had sex abroad with a local contact although more specifically in only $21 \%$ of cases was this with a new rather than a regular partner.
In our study $28.4 \%$ of subjects admitted to casual sex abroad with a new partner. This figure is much higher than the $5 \%$ reported from the community study ${ }^{10}$ and closer to the $21 \%$ reported in the London GUM study. ${ }^{6}$ The percentage of clinic attenders $(7 \cdot 3 \%)$ that reported travel abroad, is likely to be an underestimate because little is known about those who refused to participate, since the questionnaire was self-administered.

We found that, for a sub-group where sufficient data were available, $72 \%$ of visits were to Europe where $37 \%$ had consistently used condoms. Travel to Africa and to S.E. Asia accounted for only $3.7 \%$ of visits. Fortunately no new partners were reported for the subgroup visiting African destinations although in the S.E. Asian destinations only one out of the three subjects reported condom use. In view of the known link of travel to S.E. Asian destinations and sex-tourism this finding is cause for concern. Unfortunately no data are available for commercial sexual contacts abroad.

Increasing the number of casual sexual contacts will inevitably increase exposure to STDs. We found that of subjects who admitted to casual sex with a new partner abroad $29 \%$ had multiple partners. The likelihood of casual sex with more than one new partner did not vary by gender, race/ethnicity, type of visit or type relationship (heterosexual or homosexual).

Little research has been published on the relationship between ethnicity and partner choice in GUM subjects as a group. Subjects had been asked the country of origin of their partners abroad. This allowed analysis of partner choice as either UK or non-UK. This grouping distinguishes between those who would have had casual sex with "local" partners or other foreign nationals from those whose partners were from the UK. It was found that for Caucasian study subjects, first partners were more likely to come from the UK than subjects from the other ethnic groups. Owing to small numbers, however, the confidence intervals are wide.

The Nottingham community study ${ }^{10}$ revealed that only $30 \%$ (5 out of 17) had exclusively used condoms. This is lower than the proportion $(41 \cdot 7 \%)$ of subjects who claimed to have always used condoms in our study. In other studies condom use has been variously reported as $19 \%^{2}$ (14 out of 74 ) and $32 \% .^{7}$ Daniels et al reported condom use in $25 \%$ of women, $58 \%$ of heterosexual men and $71 \%$ of homosexual men with casual partners abroad. ${ }^{6}$ Thus, the finding of only four in 10 people protecting themselves in our study group is disappointing but in keeping with other reports.

In conclusion the results of this study confirm that sexual risk-taking behaviour occurs in significant proportion of patients attending a GUM clinic in a provincial UK setting to a degree that gives cause for concern. Risktaking behaviour was not confined to being male or female or by type of travel (holiday or business). Further research is necessary to clarify relationship between ethnicity and type 
of relationship, to allow targetable risk factors for effective health promotion messages to be developed.

1 Communicable Disease Reports Weekly. Communicable Disease Surveillance Centre. Volume 5, no 42, 20 Disease Surveillance Centre. Volume 5, no 42, 20

October 1995.

Hawkes S, Malin A, Araru T, Mabey D. HIV infection among heterosexual travellers attending the Hospital for Tropical diseases, London. Genitourin Med 1992;68: 309-11. 3 Ellis CJ. HIV infection and travel. BMF 1990;301:

4 Behrens RH, Porter JDH. HIV infection and foreign travel. $B M F$ 1990;301:1217.
5 Porter JDH, Stanwell-Smith R, Lea G. Travelling hopefully, returning ill. Editorial. BMF 1992;304:1324.

6 Daniels DG, Kell P, Nelson MR, Barton SE. Sexual behaviour amongst travellers: a study of genitourinary medicine clinic attenders. Int $₹$ STD AID S 1992;3:437-8.

7 Lister P, Robinson A. Letter; STD in travellers presenting to a GUM clinic. Int $₹$ STD AIDS 1993;4:59-61.

8 Tveit K-S, Nilsen A, Nyfors A. Casual sexual experience abroad in patients attending an STD clinic and at high abroad in patients attending an STD clinic and at high

9 Stricker M, Steefen R, Hormung R, et al. Fluechtige sexualle Kontakte von Schweizer Touriesten in den Tropen. Muenchner Medizinische Wochenschrift 1990;132:175-8.

10 Gillies P, Slack R, Stoddart N, Conway S. HIV-related risk behaviour in UK holiday-makers. Correspondence. AIDS 1992;6:339-41. 